\title{
PERMINTAAN REKREASI GILI TRAWANGAN DAN PEMBANGUNAN DAERAH
}

\author{
Awan Setya Dewanta dan Lalu Muhammad Satya Adji Fadiar \\ Fakultas Ekonomi, Universitas Islam Indonesia \\ Email:
}

\begin{abstract}
ABSTRAK
Penelitian ini dilakukan dengan tujuan untuk mengetahui adakah pengaruh dan seberapa pengaruh dari pendapatan wisatawan, biaya perjalanan, pesona alam, dan fasilitas rekreasi terhadap permintaan rekreasi di Gili Trawangan. Peningkatan jumlah wisatawan akan mendorong pertumbuhan ekonomi dan peningkatan pembangunan daerah. Data penelitian merupakan data primer dengan teknik pengambilan sampel acak sederhana (simple random sampling). Metode yang digunakan dalam penelitian ini adalah metode travel cost dengan alat analisis Regresi Poisson. Pengujian model dalam penelitian ini menggunakan uji rasio likelihood dan uji Wald. Hasil penelitian menunjukkan bahwa: (I) semua variabel independen dalam penelitian ini berpengaruh signifikan terhadap permintaan rekreasi di Gili Trawangan, (2) permintaan rekreasi di Gili Trawangan dapat dijelaskan oleh semua variabel independen sebesar 46 persen dan 54 persen dijelaskan oleh variabel independen di luar model.
\end{abstract}

Kata kunci: biaya perjalanan, regresi Poisson

\begin{abstract}
This study wasconducted to determinethe effectis there and how the effect of touristre venue, cost of travel, natural charm, and recreational facilitiesfor recreation demandin Gili Trawangan. Increasing the number oftourists willboost economic growthandincrease regional development. The research datais the primary data with random sampling techniques (simple random sampling). The method usedin this studyis thetravel costmethodwith Poisson regression analysis tools. Testingthe modelin this studyusing alikelihoodratio testand Waldtest. The results showedthat: (I) allin dependent variables in this studya significant effect ondemand forrecreationin Gili Trawangan, (2) demand for recreationin Gili Trawangan can be explained by all the independent variablesby 46 percentand54percentis explained by the independent variables outside the model.
\end{abstract}

Kata kunci : travel cost, regresi Poisson 


\section{PENDAHULUAN}

Proses pembangunan ekonomi di suatu daerah akan mengakibatkan terjadinya pergeseran struktur perekonomian daerah. Struktur perekonomian dicerminkan oleh kontribusi dari masing-masing sektor terhadap nilai PDRB. Strukturperekonomian di Provinsi NTB pada tahun 2013 mengalami perubahan jika dibandingkan dengan tahun 2005, gambaran tersebut dapat dilihat pada gambar 1 berikut ini.

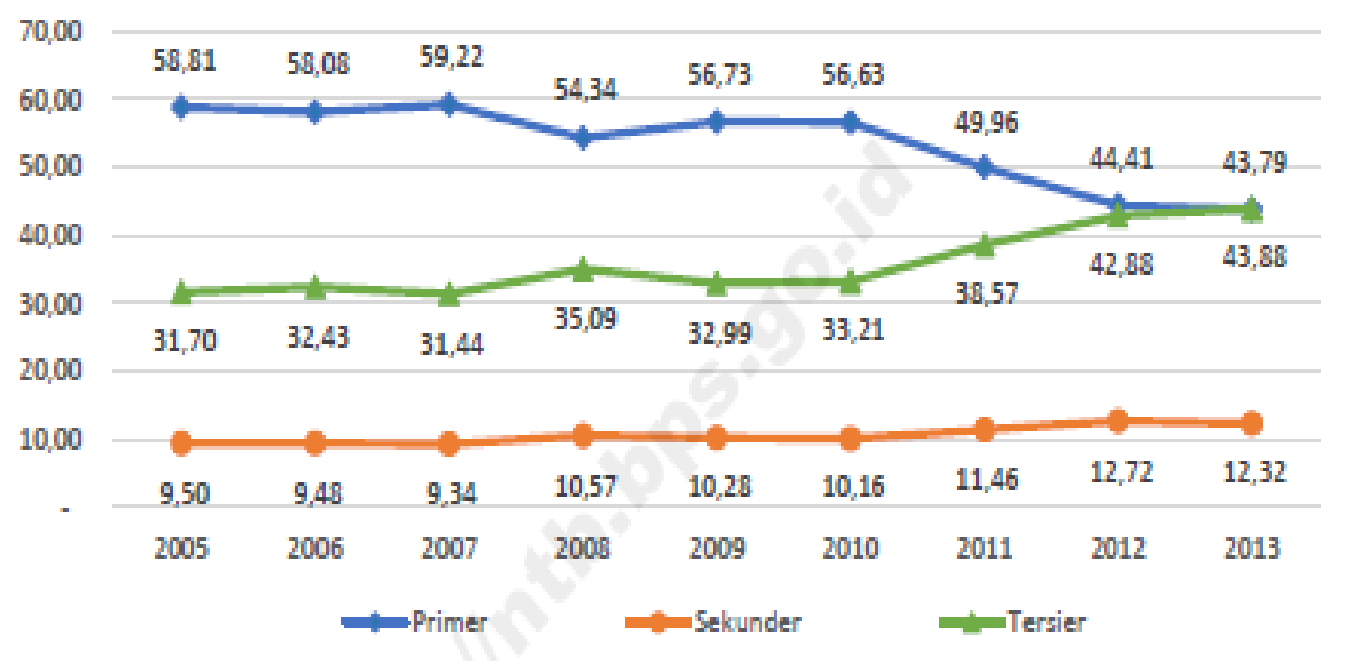

Gambar 1. Kontribusi Sektor Primer, Sekunder, dan Tersier Tahun 2005-2013

Sumber: PDRB NTB Menurut Lapangan Usaha Tahun 2013, Badan Pusat Statistik, NTB.

Pada tahun 2012 sektor primer mendominasi dengan nilai kontribusi sebesar 44,41persen, akan tetapi pada tahun 2013 kontribusinya mengalami sedikit penurunan menjadi43,79 persen. Penurunan kontribusi sektor primer selama beberapa tahun terakhirdikarenakan menurunnya nilai tambah yang dihasilkan oleh sektor pertambangan danpenggalian, khususnya subsektor pertambangan non migas. Meskipun pada tahun 2013sektor pertambangan dan penggalian mengalami peningkatan nilai tambah, namun belummampu meningkatkan kontribusinya terhadap pembentukan PDRB Provinsi NTB secarakeseluruhan karena peningkatan nilai tambah sektor pertanian lebih besar dibandingkanpeningkatan pada sektor pertambangan dan penggalian.
Sektor yang sedang meningkat dan memberikan kontribusi terbesar dalam perekonomian adalahsektor tersier. Padatahun 2012, sektro tersieratau jasa memberikan kontribusi sebesar 42,88 persen,kemudian meningkat menjadi 43,88 persen pada tahun 2013. Peningkatan ini menggesersektor primer menjadi sektor terbesar kedua penyumbang nilai tambah di Provinsi NTBmeskipun selisihnya sangat kecil.Dalam kelompok sektor tersier, kontribusi terbesar diberikan oleh sektorperdagangan, hotel dan restoran yaitu sebesar 16,96 persen, diikuti oleh sektor jasajasasebesar 13,36 persen. Sedangkan sektor tersier lainnya yaitu sektor pengangkutan \&komunikasi dan sektor bank, usaha persewaan \& jasa perusahaan masingmasingmenyumbang sebesar 7,69 persen dan 5,87 persen dalam pembentukan PDRB ProvinsiNTB tahun 2013.Dalam sektor jasa ini, 
sektor perdagangan, hotel dan restoran selama 3 tahun terakhir mengalamipeningkatan kontribusi yang cukup tinggi dari 14,69 persen pada tahun 2011 menjadi16,96 persen pada tahun 2013. Sektor ini merupakan sektor penopang sektor pariwisata yang selama ini terus dikembangkan di Provinsi Nusa Tenggara Barat sebagaisalah satu daerah tujuan wisata di Indonesia.

Berdasarkan kelompok sektor tersebut, perekonomian NTB tahun 2013 mengalamipergeseran bila dibandingkan dengan tahun-tahun sebelumnya. Hingga tahun 2012,struktur ekonomi NTB masih didominasi oleh sektor primer (sektor pertanian dan sektorpertambangan \& penggalian). Namun pada tahun 2013 ini didominasi oleh sektor tersier(sektor perdagangan hotel \& restoran, sektor pengangkutan \& komunikasi, sektor bank,usaha persewaan \& jasa perusahaan dan sektor jasa- jasa). Dengan demikian, dapat dikatakan bahwa sektor pariwisata merupakan sektor unggulan daerah Nusa Tenggara Barat. Kekuatan daya pikat pariwisata NTB ada pada wisata alamnya, sedangkan pariwisata budaya sebagai penunjangnya. Dua pulaunya memamerkan panorama alam dan budaya yang mempesona. Ibarat sebuah lukisan, kekayaan alam NTB tergambar jelas dalam sebuah pigura indah. Dari ujung Timur hingga ujung Barat, terpapar kawasan wisata cantik nan alami. Anugerah alam yang luar biasa dengan khasanah flora dan fauna yang beragam.

Berdasarkan Peraturan Daerah NTB Nomor 9 tahun 1989 tentang Pengembangan Kawasan Pariwisata di Nusa Tenggara Barat, terdapat 15 kawasan pariwisata yang akan dikembangkan. Lima belas kawasan wisata potensial yang menawarkan panorama cantik memesona, eksotik dan alami, sembilan berada di Pulau Lombok dan enam lainnya di Pulau Sumbawa. Objek wisata NTB ini menawarkan pilihan mulai dari wisata alam bahari, wisata alam pegunungan dan wisata budaya.Pesona tiga Gili merupakan objek wisata unggulan pemerintah NTB yang terdiri dari Gili Trawangan, Gili Air, dan Gili Meno. Pesona tiga Gili ini berada di sebelah barat pulau Lombok yang merupakan wilayah pemerintahan Kabupaten Lombok Utara. Diantara tiga Gili tersebut, Gili Trawangan merupakan destinasi wisata yang paling ramai dan menjadi destinasi wisata yang paling digemari wisatawan untuk dikunjungi.

Untuk mendukung peraturan tersebut, identifikasi faktor penentu permintaan wisata diperlukan. Untuk itu, penelitian ini dilakukan dengan mengambil kasus kunjungan wisata di Gili Trawangan.

Adapun hipotesis dalam penelitian ini antara lain:

a. Didugapenghasilan per bulan wisatawan, biaya perjalanan wisatawan, keindahan alam, fasilitas rekreasi, asal wisatawan, lama menginap berpengaruh terhadap permintaan rekreasi di Gili Trawangan

b. Didugapenghasilan per bulan wisatawan, biaya perjalanan wisatawan, keindahan alam, fasilitas rekreasi, asal wisatawan, lama menginap mampu menjelaskan fungsi permintaan rekreasi di Gili Trawangan

\section{METODE PENELITIAN}

\section{Kajian Pustaka dan Model Regresi}

Penelitian tentamg permintaan wisata telah banyak dilakukan. Santosa (2013) melakukan analisis Permintaan Obyek Wisata Masjid Agung Semarang. Penelitian ini menggunakan metode travel cost dalam melakukan penelitiannya dengan satu variabel terikat (Dependent Variable) yakni jumlah permintaan wisata ke Masjid Agung Semarang dan sembilan variabel bebas (independent Variable) yakni variabel biaya perjalanan ke 
obyek wisata Masjid Agung Semarang, variabel biaya perjalanan ke obyek wisata lain (kawasan Demak), variabel pendapatan individu, variabel lama perjalanan, variabel waktu, variabel umur, variabel fasilitas, dan variabel keindahan Masjid Agung.Penelitian ini menyimpulkan bahwa tiga variabel yang berpengaruh secara signifikan yaitu variabel biaya perjalan ke obyek wisata Masjid Agung Semarang, variabel lama perjalanan, dan variabel keindahan Masjid Agung. Variabel bebas lain tidak sifnifikan mempengaruhi pemintaan wisata ke Masjid Agung.

Nurhayati et al (2013) melakukan Valuasi Nilai Ekonomi Taman Nasional Bunaken. Penelitian tersebutmenganalisis faktor-faktor yang mempengaruhi nilai kesediaan masyarakat membayar manfaat dari keberadaan Taman Nasional Bunaken. Penelitian tersebut menggnakan jumlah kunjungan sebagai variable terikat, dan enam variable bebas. Variabel bebas yang digunkan adalah biaya perjalanan, biaya perjalanan ke obyek wisata lain, pendapatan pengunjung, jarak, umur, paritas daya beli wisatawan mancanegara. Penelitian ini menyimpulkan bahwa: (1) Untuk wisatawan dalam negeri, faktor yang mempengaruhi secara signifikan nilai kesediaan membayar wisatawan nusantara membayar manfaat dari keberadaan Taman Nasional Bunaken adalah jumlah biaya yang dikeluarkan selama perjalanan wisata ke Taman Nasional Bunaken, sedangkan faktor jumlah biaya perjalanan ke obyek wisata lain, pendapatan, jarak, dan umur tidak berpengaruh secara signifikan terhadap nilai kesediaan membayar wisatawan nusantara membayar manfaat dari keberadaan Taman Nasional Bunaken; (2)Untuk wisatawa manca negara, faktor yang mempengaruhi secara signifikan nilai kesediaan membayar wisatawan mancanegara membayar manfaat dari keberadaan Taman Nasional Bunaken dan nilai tukar paritas daya beli negara asal wisatawan mancanegara terhadap Dollar, sedangkan faktor jumlah biaya perjalanan ke obyek wisata lain, pendapatan, jarak, dan umur tidak berpengaruh secara signifikan terhadap nilai kesediaan membayar wisatawan nusantara membayar manfaat dari keberadaan Taman Nasional Bunaken.

Kedua penelitian di atas menggunakan analisis regresi OLS, padahal variabel yang digunakan adalah variabel diskrit sehingga penggunaan alat analisis regresi perlu disesuaikan. Alat regresi yang digunakan untuk variabel diskrit adalah regresi Poisson. Penggunaan regresi Poisson ini pernah digunakan pada permintaan wisata Kaliurang (Dewanta, 2010). Penelitian pada permintaan wisata Kaliurang tersebut menggunakan regresi Poisson untuk mengukur atau menduga fungsi permintaan wisata alam di Kaliurang, Sleman, Yogyakarta.

Regresi poisson adalah sebuah metode statistika yang digunakan untuk menganalisis hubungan antara sebuah variabel dependen dengan satu atau lebih dari satu variabel independen (Greene, 2003). Variabel dependen yang digunakan sama dengan analisis regresi pada umumnya yakni variabel random kontinu, namun dalam regresi poisson nilai variabel independennya diasumsikan berdistribusi poisson.

Analisis regresi poisson digunakan untuk menganalisis hubungan antara sebuah variabel dependen yang menyatakan data terhitung atau data count berdistribusi poisson dengan satu atau lebih variabel independen. data count yang dimaksud misalnya adalah banyaknya kejadian dalam interval waktu, ruang, atau volume tertentu. Dalam analisis regresi poisson, variabel independen yang digunakan dapat berjenis kontinu atau kategorik. Hubungan antara variabel dependen dan variabel independen tersebut dijelaskan oleh model regresi poisson. 
Pada model regresi poisson, biasanya link function yang digunakan adalah log yaitu $\ln _{\left(\mu_{i}\right)}=n_{i}$, sehingga fungsi hubungan untuk model regresi poisson mempunyai logaritma seperti pada persamaan (1) dan persamaan (2).

$$
\begin{gathered}
\ln E\left(y_{i} \mid x_{i}\right)=\ln \left(\mu_{i}\right)=n_{i}= \\
\beta_{0}+\beta_{1} x_{1}+\beta_{2} x_{2}+\ldots+\beta_{k} x_{i k} \\
\mu_{i}=\exp \left(x_{i}^{T} \boldsymbol{\beta}\right)= \\
\exp \left(\beta_{0}+\beta_{1} x_{i 1}+\beta_{2} x_{i 2}+\ldots+\beta_{k} x_{i k}\right)
\end{gathered}
$$

\section{Jenis dan Cara Pengumpulan Data}

Penelitian ini menggunakan data primer sebagai sumber informasi untuk memberikan gambaran spesifik mengenai obyek penelitian. Data primer adalah data yang diperoleh atau dikumpulkan oleh peneliti secara langsung dari sumber datanya. Dalam penelitian ini, peneliti menggunakan teknik penyebaran kuisioner dengan jenis kuisioner tertutup yakni suatu daftar yang berisikan rangkaian pertanyaan mengenai masalah atau bidang yang akan diteliti dengan pertanyaan yang berbentuk pilihan ganda, ya-tidak, skala penilaian, dan daftar cek.

Pengambilan sampel dilakukan dengan teknik simple random sampling (sampling acak sederhana) yaitu teknik yang termasuk dalam probability sampling dengan metode pengambilan sampel acak. Pada teknik ini, pengambilan sampel dilakukan dengan cara menyebarkan kuisioner secara acak kepada wisatawan nusantara yang sedang berekreasi di Gili Trawangan.

Penelitian ini menggunakan variabel terikat (dependent variable) adalah permintaan rekreasi di Gili Trawangan yang diukur dari frekuensi kunjungan yang dilakukan oleh wisatawan nusantara selama satu tahun. Untuk variabel bebas (Independent Variable) meliputi penghasilan per bulan, biaya perjalanan, keindahan alam, fasilitas rekreasi, asal pengunjung, dan lama menginap.

\section{HASIL PENELITIAN DAN PEMBAHASAN}

Setelah melakukan pengolahan data, diperoleh nilai untuk parameter $\beta_{0}, \beta_{1}, \beta_{2}, \beta_{3}$,

\begin{tabular}{|c|c|c|c|}
\hline Parameter & $\begin{array}{l}\text { Coefficien } \\
t\end{array}$ & $\begin{array}{l}\text { Std. } \\
\text { Error }\end{array}$ & $\mathrm{Wj}$ \\
\hline $\begin{array}{l}\text { Konstanta } \\
\left(\beta_{0}\right)\end{array}$ & 1.285664 & $\begin{array}{r}0.18784 \\
0\end{array}$ & \\
\hline $\begin{array}{l}\text { Pendapata } \\
\mathrm{n}\left(\beta_{1}\right)\end{array}$ & $3.27 \mathrm{E}-08$ & 1.83E-08 & $\begin{array}{r}3.20702 \\
2 \\
\end{array}$ \\
\hline Harga $\left(\beta_{2}\right)$ & $-1.99 \mathrm{E}-07$ & 7.74E-08 & $\begin{array}{r}6.60979 \\
5 \\
\end{array}$ \\
\hline $\begin{array}{l}\text { Keindahan } \\
\text { Alam }\left(\beta_{3}\right)\end{array}$ & -0.338786 & $\begin{array}{r}0.19883 \\
7\end{array}$ & $\begin{array}{r}2.90305 \\
9\end{array}$ \\
\hline $\begin{array}{l}\text { Fasilitas } \\
\text { Rekreasi } \\
\left(\beta_{4}\right)\end{array}$ & 0.418185 & $\begin{array}{r}0.15989 \\
8\end{array}$ & $\begin{array}{r}6.83988 \\
7\end{array}$ \\
\hline $\begin{array}{l}\text { Asal } \\
\text { Pengunjun } \\
\mathrm{g}\left(\beta_{5}\right)\end{array}$ & -0.720496 & $\begin{array}{r}0.19126 \\
0\end{array}$ & $\begin{array}{r}14.1909 \\
8\end{array}$ \\
\hline $\begin{array}{l}\text { Lama } \\
\text { Menginap } \\
\left(\beta_{6}\right)\end{array}$ & 0.256862 & $\begin{array}{r}0.14139 \\
8 \\
\end{array}$ & $\begin{array}{r}3.29998 \\
0\end{array}$ \\
\hline $\log L_{0}$ & -213.1538 & & \\
\hline $\log L_{1}$ & -167.1170 & & \\
\hline
\end{tabular}
$\beta_{4}, \beta_{5}, \beta_{6}$ pada tabel berikut:

Tabel 2 Hasil Regersi dan Nilai Parameter Regresi Poisson

Model regresi poisson yang dihasilkan adalah:

$$
\begin{aligned}
& \ln \left(\widehat{\mu}\left(X_{1}, X_{2}, \ldots, X_{6}\right)\right)=\beta_{0}+\beta_{1} x_{1}+\beta_{2} x_{2}+ \\
& \beta_{3} x_{3}+\beta_{4} x_{4}+\beta_{5} x_{5}+\beta_{6} x_{6} \\
& 1.285664+3.27 \mathrm{E}-08 x_{1}-1.99 \mathrm{E}- \\
& 07 x_{2}-0.338786 x_{3}+0.418185 x_{4}-0.720496 x_{5}+ \\
& 0.256862 x_{6}
\end{aligned}
$$


Selanjutnya diuji signifikansi model untuk mengetahui apakah model tersebut dapat digunakan untuk menggambarkan hubungan antara permintaan kunjungan rekreasi di Gili Trawangan dengan pendapatan, harga, keindahan alam, fasilitas rekreasi, alamat asal, dan lama menginap.

Hipotesis: $\quad H_{0}: \beta_{1}=\beta_{2}=\beta_{3}=\beta_{5}=$ $\beta_{9}=\beta_{10}=0$

$$
\begin{array}{r}
H_{1}: \exists \beta_{j} \neq 0 \\
; j=1,2,3,5,9,10
\end{array}
$$

Statistik uji yang digunakan untuk menguji hipotesis diatas adalah statistik uji rasio likelihood (Hertriyanti, 2006).

$$
\mathrm{G}=2\left(\log L_{1}-\log L_{0}\right)
$$

di mana: $\log L_{1}$ adalah nilai likelihood dari model yang mengandung seluruh variabel independen, dan $\log L_{0}$ adalah nilai likelihood dari model yang tidak mengandung variabel independen, yang ditunjukkan oleh nilai Restr. Log likelihood dalam eviews.

Dari hasil olah program eviews pada tabel 1 diperoleh:

\subsection{8}

$$
\log L_{1}=-167.1170, \quad \log L_{0} \quad=\quad-
$$

Oleh karena itu: $G=2[-167.1170-$ $(-213.1538)]=92.0736$. Berdasarkan tabel chi-squares dengan tingkat signifikansi 0.10 dan derajat bebas 6 diperoleh nilai $X_{0.10 ; 6}^{2}=$ 15.987. Nilai $\mathrm{G}=92.0736>X_{0.10 ; 6}^{2}=15.987$, maka $H_{0}$ ditolak pada tingkat signifikansi 0.10 . Model tersebut dapat digunakan untuk menggambarkan hubungan antara permintaan kunjungan rekreasi ke Gili Trawangan dengan pendapatan, harga, keindahan alam, fasilitas rekreasi, alamat asal, dan lama menginap.

Selanjutnya dilakukan pengujian signifikansi masing-masing parameter dari model regresi poisson.
Hipotesis:

$$
\begin{gathered}
H_{0}: \beta_{j}=0 \quad j=1,2,3,5,910 \\
H_{1}: \beta_{j} \neq 0
\end{gathered}
$$

Statistik uji Wald: $\quad W_{j}=\left(\frac{\widehat{\beta}_{j}}{\hat{S} E\left(\widehat{\beta}_{j}\right)}\right)^{2}$

Berdasarkan output program eviews pada tabel 1 diperoleh:

$$
\begin{aligned}
W_{1} & =\left(\frac{\widehat{\beta}_{1}}{\hat{S} E\left(\widehat{\beta}_{1}\right)}\right)^{2}=3.207022, W_{2}= \\
\left(\frac{\widehat{\beta}_{2}}{\hat{S} E\left(\widehat{\beta}_{2}\right)}\right)^{2} & =6.609795 \\
W_{3} & =\left(\frac{\widehat{\beta}_{3}}{S E\left(\widehat{\beta}_{3}\right)}\right)^{2}=2.903059, W_{5}= \\
\left(\frac{\widehat{\beta}_{5}}{\hat{S} E\left(\widehat{\beta}_{5}\right)}\right)^{2} & =6.839887 \\
W_{9} & =\left(\frac{\widehat{\beta}_{9}}{S E\left(\widehat{\beta}_{9}\right)}\right)^{2}=14.19098, W_{10}= \\
\left(\frac{\widehat{\beta}_{10}}{S E\left(\widehat{\beta}_{10}\right)}\right)^{2} & =3.299980
\end{aligned}
$$

Berdasarkan tabel chi-squres dengan tingkat signifikansi 0.10 dan derajat bebas 1 diperoleh nilai $x_{0.10 ; 1}^{2}=2.706$. Parameter $\beta_{1}, \beta_{2}$, $\beta_{3}, \beta_{4}, \beta_{5}, \beta_{6}$ signifikan pada tingkat signifikansi 0.10 . Artinya, semua variabel bebas signifikan mempengaruhi permintaan permintaan rekreasi di Gili Trawangan.

Karena seluruh parameter dalam model regresi poisson signifikan pada tingkat signifikansi 0.10, maka seluruh parameter dapat diinterpretasi.Nilai koefisien variabel penghasilan pengunjung perbulan $\left(X_{1}\right)$ sebesar 3.27E-08 menyatakan bahwa apabila variabel penghasilan pengunjung perbulan mengalami peningkatan sebesar $\mathrm{Rp} 100.000 .000$, maka akan meningkatkan jumlah kunjungan wisatawan sebesar 3.27 kali. Hal ini menjelaskan bahwa semakin tinggi penghasilan wisatawan maka frekuensi permintaan rekreasi akan semakin meningkat, sebaliknya jika penghasilan wisatawan mengalami penurunan maka frekuensi permintaan rekreasi juga akan menurun. Hal ini 
berarti bahwa objek wisata Gili Trawangan merupakan barang normal.

Nilai koefisien variabel biaya perjalanan ke Gili Trawangan $\left(X_{2}\right)$ sebesar -1.99E-07 menyatakan bahwa apabila variabel biaya perjalanan ke Gili Trawangan mengalami peningkatan sebesar $\mathrm{Rp} 10.000 .000$, maka akan menurunkan frekuensi permintaan rekreasi ke Gili Trawangan sebesar 1.99 kali. dengan asumsi bahwa variabel lainnya dianggap nol atau konstan. Hal ini bahwa semakin tingginya biaya yang dikeluarkan wisatawan (biaya transportasi, tiket masuk, penginapan, dan lain-lain) dan tidak dibarengi dengan melakukan inovasi dalam menciptakan atraksi rekreasi baru maka akan berdampak pada menurunnya frekuensi rekreasi ke Gili Trawangan.

Koefisien variabel keindahan alam $\left(X_{3}\right)$ bernilai negatif sebesar -0.338786, ini mengartikan bahwa setiap kenaikan persepsi wisatawan terhadap keindahan alam sebesar 1 unit akan menurunkan permintaan rekreasi di Gili Trawangan 0.338786 kali dengan asumsi variabel lainnya tetap. Penurunan ini merupakan anomali yang belum dapat dijelaskan secara nyata. Hal ini perlu penelitian yang lebih lanjut mengenai hal tersebut. Namun, untuk menjawab mengapa keindahan alam obyek wisata dapat menurunkan frekuensi kunjungan. Untuk sementara peneliti menyimpulkan bahwa hal ini bisa terjadi apabila pengunjung Gili Trawangan tidak bertujuan melihat keindahan alam Gili Trawangan.

Nilai koefisien variabel fasilitas rekreasi $\left(X_{4}\right)$ sebesar 0.418185 , hal ini berarti apabila persepsi wisatawan mengenai fasilitas meningkat 1 unit maka akan meningkatkan permintaan rekreasi ke Gili Trawangan sebesar 0.418185 kali dengan asumsi variabel lainnya dianggap nol atau konstan. Ini membuktikan bahwa ketersediaan fasilitas rekreasi yang baik akan menentukan kenyamanan wisatawan selama berada di Gili Trawangan yang pada akhirnya akan meningkatkan frekuensi permintaan kunjungan ke Gili Trawangan.

Nilai koefisien variabel asal pengunjung $\left(X_{5}\right)$ sebesar -0.720496 menyatakan bahwa alamat asal wisatawan mempengaruhi permintaan rekreasi di Gili Trawangan, dimana apabila kegiatan rekreasi dilakukan oleh wisatawan yang berasal dari luar Lombok maka permintaan rekreasinya akan menurun sebesar - 0.720496 kali dengan asumsi variabel lainnya bernilai nol atau konstan. Hal ini karena nilai $\beta_{5}=-0.720496$ yang mendekati nilai 1 , dimana angka " 1 " dalam dummy ditujukan untuk wisatawan yang berasal dari luar Lombok.

Nilai koefisien variabel lama menginap $\left(X_{6}\right)$ sebesar 0.256862 menyatakan bahwa lama menginap mempengaruhi permintaan rekreasi di Gili Trawangan, dimana apabila pengunjung berada di Gili Trawangan kurang dari 24 jam maka permintaan rekreasi Gili Trawangan akan naik sebesar 0.256862 kali dengan asumsi variabel lainnya bernilai nol atau konstan. Hal ini karena nilai $\beta_{6}=$ 0.256862 yang mendekati nilai 0 , dimana angka "0" dalam dummy ditujukan untuk wisatawan uang berkunjung kurang dari 24 jam.

\section{KESIMPULAN DAN IMPLIKASI}

1. Hasil regresi Poisson dapat membuktikan penghasilan per bulan wisatawan, biaya perjalanan wisatawan, keindahan alam, fasilitas rekreasi, asal wisatawan, lama menginap berpengaruh terhadap permintaan rekreasi di Gili Trawangan

2. Sebesar $46 \%$ variabel bebas (0enghasilan per bulan wisatawan, biaya perjalanan wisatawan, keindahan alam, fasilitas rekreasi, asal wisatawan, lama menginap) mampu menjelaskan fungsi 
permintaan rekreasi di Gili Trawangan. Hal ini ditunjukan oleh nilai koefisien determinasi $R$ square $\left(R^{2}\right)$ sebesar 0.460205 yang berarti 46 persen permintaan rekreasi di Gili Trawangan secara bersama-sama dapat dijelaskan oleh variasi dari keenam variabel independen yaitu pendapatan wisatawan, biaya perjalanan yang dikeluarkan wisatawan, keindahan alam, fasilitas rekreasi, alamat asal wisatawan, dan lama menginap.

Implikasi dari penelitian ini adalah wisata Gili Trawangan menarik bagi wisatawan bukan berasal dari pulau Lombok, sehingga alat transportasi dan sarana transportasi menuju ke obyek wisata perlu ditingkatkan dan dipermudah agar biaya transportasi menjadi semakin murah, disamping membangun sarana penginapan yang nyaman. Peningkatan wisata ke Gili Trawangan akan memberikan kontribusi terhadap pertumbuhan ekonomi dan pembanguan daerah.

\section{UCAPAN TERIMA KASIH}

Ucapan terima kasih diberikan kepada para wisatawan Gili Trawanga tyang telah bekerjasama dan meluangkan waktu menjawab pertanyaan penelitian ini. Ucapan juga diaturkan kepada pemerintah daerah, Dinas Pariwisata, dan para petugas dan pegawai tempat wisata Gili Trawangan, serta pihak-pihak lain yang membantu penelitian ini.

\section{DAFTAR PUSTAKA}

Dewanta, Awan Setya. 2010. Valuation of Mount Merapi National Park: A Travel Cost Analysis. Economics Journal of Emerging Markets. Vol 2, No.1. Center for Economics Studies Faculty of Economics Universitas Islam Indonesia

Gili Trawangan. Diakses pada tanggal 24 november dari situs id.wikipedia.org Greene, W. H. 2003.Econometric Analysis, Prentice Hall , Upper Saddle River, NJ.
Nurhayati Samsudin, Budiono, dan Wawan Hermawan. 2013. "Valuasi Ekonomi Taman Nasional Bunaken, Aplikasi Travel Cost Method." Jurnal MET. Universitas Padjajaran.

Santosa. 2013. "Analisis Permintaan Obyek Wisata Masjid Agung Semarang" Jurnal Ekonomi Pembangunan, Volume 2, Nomor 2, Halaman 1- 15. 